\section{RETROGRADE NEEDLING.}

A New Technique for Inserting Radium Needles in Carcinoma of the Tongue.

BY

K. H. PRTDIE, M.B., B.S., M.R.C.S., HOUSE-SURGEON, BRISTOL ROYAL INFIRMARY. (IVith Special Plate.)

A NEw technique for inserting radium needles in carcinoma of the tongue has been devised to overcome the difficulties which are met with when needles are inserted by the usual technique.

Owing to the mobility of the tongue the movements of deglutition may displace needles inserted in the edges of a growth. In some cases the needles have been dislodged and swallowed, and in others they have been displaced, necessitating removal before the full dosage has been given. The back of the tongue, too, especially the epiglottic region, is very inaccessible, and great difficulty may be experienced in placing the needles in the growth and keeping them there. In addition, the deeper parts of the growth are too far from the needles to be affected by the radium.

The following case of carcinoma in the dorsum of the tongue illustrates the new technique. The growth was in the epiglottic region and the base of the tongue was infiltrated. The ulcerated arca could not be seen from the mouth without the aid of a, mirror. The radium needles used were shaped as shown in Fig. 1. They were threaded with Pagenstacher No. 2, knotted once.

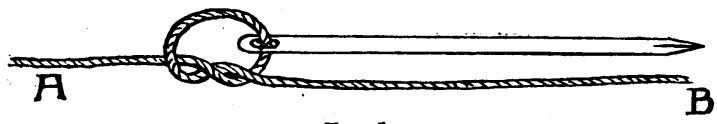

FIG. 1.

The tongue was drawn forward and a Greig-Smith abdominal needle was introduced into the space between the hyoid bone and the mandible, a finger introduced into the mouth guiding the needle so that it came out through the margin of the growth into the mouth. The end $A$ of the thread attached to the radium needle was then threaded through the Greig-Smith needle, which was withdrawn through the skin of the neck and detached. By pulling on the thread the radium needle was drawn backwards into the growth till the point just disappeared. $A$ small piece of rubber tube was threaded on the end $A$ where it came out of the skin to indicate the depth of the needle in the growth. A piece of rubber tubing was threaded on to end B to protect the lip, and the ends $\mathbf{A}$ and $\mathbf{B}$ were knotted together loosely, forming a complete loop (Fig. 2). In a similar manner other needles were placed all round the growth.

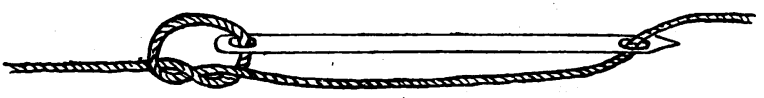

FIG. 2.

By pulling the ends $\mathbf{A}$ or $\mathbf{B}$ the needles can be made to travel either down into the deeper parts of the tongue and glands and finally out through the skin in the submaxillary triangle, or up in the mouth.

By transfixing the growth the deeper parts of it and the glands themselves may be treated after the needles have been for some time in the margin of the growth, and when supplies of radium are small a large area comes within reach of the needles when they are gradually pulled through the growth-for instance, one inch every three or five days.

A needle with two eves (Fig. 3) is suggested for this technique, which has also been used with success in the treatment of new growths in parts of the body other than the tongue. For instance, when only four or five needies were availahle, a large sarcomatous mass on the parietal peritoneum was treated by this method, the needles beins made to travel in four stages of one inch every three days.

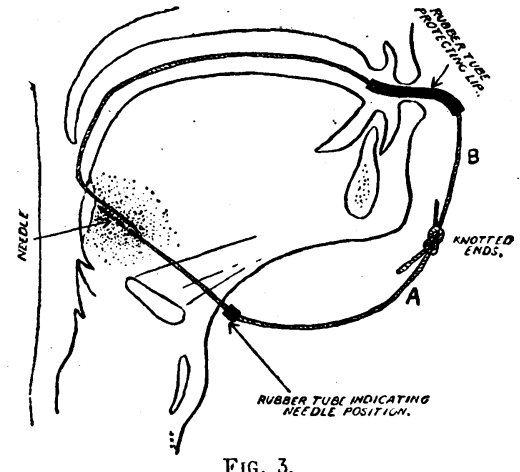

The advantages of this technique are:

1. The ease with which radium viccalles ean bo inserted in inaccessible regions.

2. A small quantity of radium can be made to act on a large area.

3. The position of the needles is alwars known and they can be moved with great ease and anchored whero desired.

The disadvantages of the technique are:

1. Sepsis; there is always some pus and inflammation round the thread track.

2. Haemorrhage; the needle might puncture some vessel of large size, though this would be rendered unlikely by the use of two-eyed needles as suggested. In the cases treated hitherto there has been no trouble from haemorrhage.

The skiagrams reproduced in the Special Plate show radium needles in situ introduced by this technique.

\section{THE PATHOGENESIS OF PULIONARY CAVITIES.}

\section{BY}

S. Vere PEARSON, M.D.Camb., M.R.C.P., RESIDENT PHYSiCiAN, THE MUNDESLEY SANATORIUM.

(IIth Special Plate.)

Then is a possible factor in the production of excavation in the lung to which hitherto little or no attention has been drawn. For some time $I$ have felt that there is a certain amount of evidence indicating that a positive pressure of gas within an area of softening, or within a definite cavity already formed, helps to produce excavation. I have now been able to prove that this positive pressure occurs, because recently I was able to introduce a hollow needle safely straight into a largo apical cavity, which needle was attached to the ordinary manometer of a pneumothorax apparatus, and I found a positive pressure of $16 \mathrm{~cm}$. of water. From this cavity I extracted gas, and while able to reduce the pressure several centimetres I could not reduce it further, owing, apparently, to the fact that there was only an obstructed opening into the bronchus. Some two months later, on repeating the puncture of the cavity, I found that it was patent both on inspiration and during expiration. I append more precise details about this particular patient and send two photographs of his $x$-ray appearances, one taken in June, 1927, and the other in November, 1929.

There are several a priori reasons which support the likelihood of internal pressure as a factor in the pathogenesis of pulmonary cavities. Considering that cavities frequently have secretion in them, it seems reasonable to suppose that some of this may at times block the opening into the bronchial system. It is often taken for granted that a valvular opening through a hole in the lung surface into the pleural space, as occurs sometimes in spontaneous 

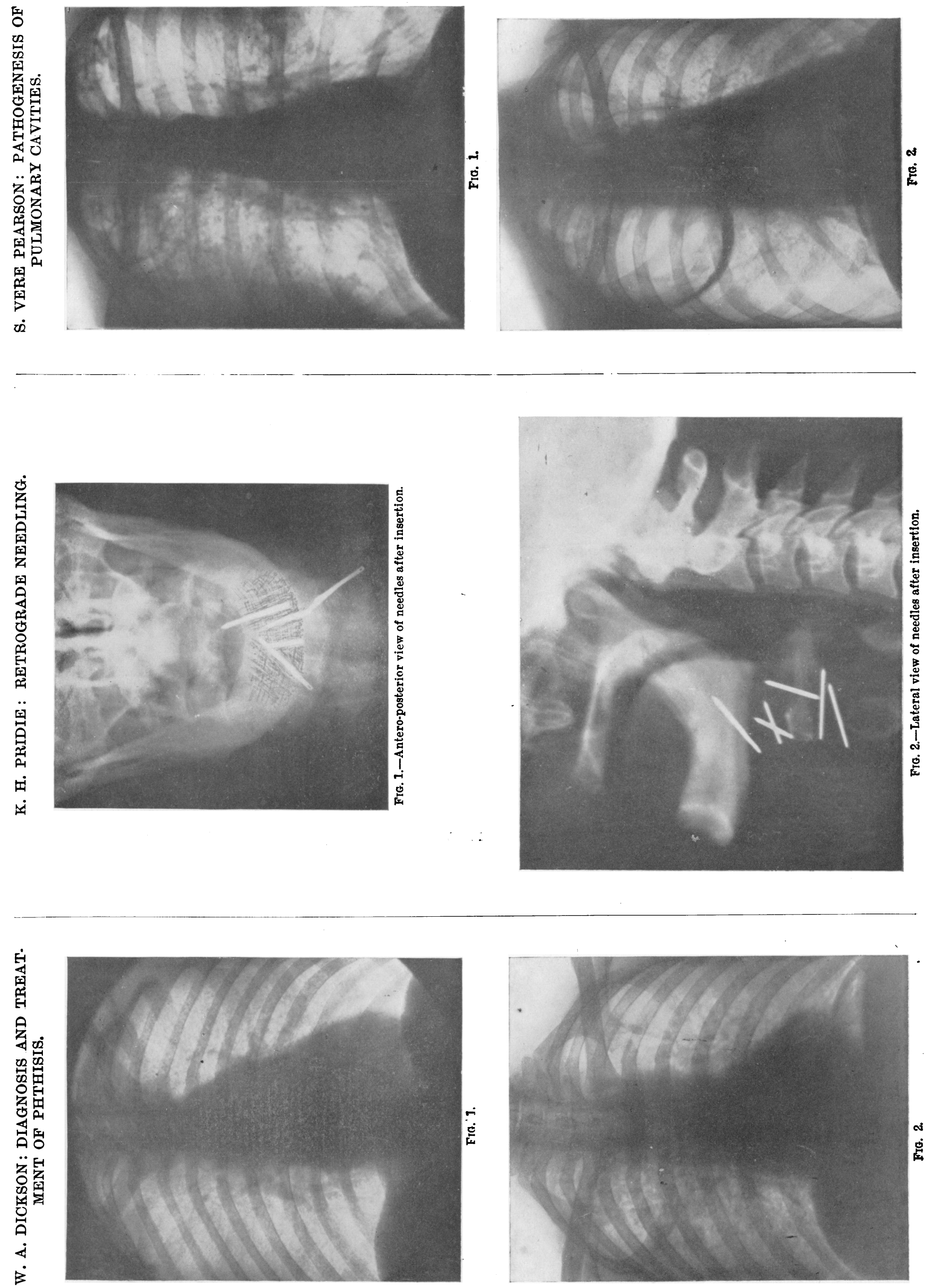
pneumothorax, frequently gives rise to a positive pressure. A similar thing may be supposed to happen when there is a valvular opening into a cavity within the lung. But it is rather doubtful whether an appreciable positire pressure call arise in either case with an open epiglottis, since respiratory movements then simply oscillate around tho atmospheric pressure-zero. It is when straining and coughing occur and the glottis is closed, with the prodrection of a higher intrabronchial pressure, sometimes reaching many (for example, 20 or 30) centimetres of pressure, that a distinct, and occasionally dangerously high, positive pressure is produced. Manometric readings I have taken in the chest of an open spontaneous pneumothorax support this view.

In connexion with these points it must be remembered that the potential pressure in the uninjured pleural cavity itself is a negative one, and in some cases highly negative. ] have found as low a pressure as - 72 (inspiratory) and - $14 \mathrm{~cm}$. (espiratory) of water at the induction of an artificial pneumothorax. It is obvious, too, that the pulmonaly tissue is of a soft and giving nature. This is increased sometimes in pulmonary tuberculosis, especially in those cases which show little tendency to fibrosis. Radiology demonstrates that cavities appear sometimes very quickly, and by the same means evidence can on rare occa-ions be brought forward to show that now and then they clear up surprisingly quickly. The fact that such a large proportion of cavities, especially of those which reach any appreciable size, are spherical is highly suggestive that internal pressure is a factor in producing excavation. I do not consider there is any evidence to lead one to suppose that gas-forming organisms produce gas in a cavity and hence set up positive pressures therein, though this is just a possibility in rare circumstances.

Mr. X., aged 38, was first admitted to the Mundesley Sanatorium in June, 1927. The first photograph shows considerable discase in the right lung, with several cavities of no mean size at the apex. There is also disease in the left lung, with small ravities at its extreme apex. The second photograph, taken on Oetober 14th, 1929, shows an improved left side with an enormous apical cavity containing a minute quantity of secretion at the bollom, and below this partially compressed lower and middle Johes. This compression was artificially produced, its inauguration dating from October 4th, 1929. We watched the cavity grow during years, and have a series of photographs, some stercoscopic. I/s extension shortly before October, 1929, was rapid.

Whon the patient was readmitted to the Mundesley Sanatorium on August 29th, 1929, and for many weeks afterwards, his condition was serious. He had considerable fever, but not much cxpectoration, only a few drachms. The outlook seemed bad. After consideration it was decided to see whether a right-sided artificial pneumothorax would compress the cavity. This decision was come to in spite of the fact that the left lung was affected, though now much better, and in spite of the fact that the two lower lobes on the right side were by this time functioning much belter and the disease in them appeared healed to a large extent. Unfortunately the pneumothorax compressed only the healthier parts, the two lower lobes, and was followed rather quickly by a large outpouring of pleural fluid. Before the fluid arose, and fecling certain that the cavity was universally adherent to the chest wall, I punctured it in the second intercostal space anteriorly with a needle attached to a manometer, and found the pressures inside ii +4 and +16 . After withdrawing $250 \mathrm{c.cm}$. of gas these were reduced to close on zero and +11 . After another 250 c.cm. was withdrawn the pressures were at; 0 and +9 . Then a further 250 c.cn., making 750 altogether, was withdrawn, but the pressures remained the same, 0 and +9 . Now the ordinary intrapleural pressures taken before and at the end of screral refills during the preceding weeks varied between -12 and +3 . They were never positive at the beginning of a refill, Those at the initial induction were -12 and -3 . On November 20 th $550 \mathrm{c.cm}$. of fluid was withdrawn from the pneumothorax cavity; and again on November 30th and on December 11th between a pint and two pints of fluid were withdrawn. By the end of the year the patient's condition was greatly improved, the temperature had come down near to normal limits, and in the carly part of 1930 the progress was continuing fairly satisfactorily.

On January 9th a second puncture was made into the cavity. On this occasion the pressures were found to be round about zcro-namely, -5 and +5 . The patient was rolled on to his left side to see whether any fluid in the cavily might reproduce a raivular opening. But no such effect resulted from the manocurre, which only depressed the oscillations to -2 and +2 . This, doubtless, was because the chief working lung, the left one, was compressed by the position of the patient, though the weight of the mediastinum falling away from the side in which the necdle was situated would tend to make the oscillations bigger in a more ordinary case.

Dr. James Lawson first pointed out that when the pationt receiving an ordinary refill during the course of maintenance of an artificial pneumothorax turns from his side on to his back with the needle in situ the oscillations are rathor less and the pressures rather higher. It was obvious that at this second puncture of $\mathbf{M r}$. $\mathbf{X}$. there was no valvular opening.

At the time of writing apicolysis or thoracoplasty is under consideration. But with a poor resisting power and an unsomen left lung, combined with the condition of the patient, which, though improved, is still far from satisfactory, these proceedings are not considered applicable, at all events during the next month or two.

REFERENCE. in British Medlical Journal, 1922, i, 309, " Note on Intrapleural Pressures

\section{DIVERTICULITIS, WITH PARTICULAR REFERENCE TO ITS DIAGNOSIS BY RADIOLOGY.*}

BY

\section{W. H. ROWDEN, M.B., Ch.B.LeEds, D.M.R.E.CAMB. (IVith Special Plate.)}

Diverticula may occur or derelop in any part of the alimentary canal. They may occur in the pharynx; in the upper, middle, and lower thirds of the oesophagus; in the cardiac or pyloric regions of the stomach, where, on radiological examination, an individual diverticulum may be mistaken for the crater of a gastric ulcer; in the first, second, and third parts of the duodenum; and in the region of the duodeno-jejunal flexure. Meckel's diverticulum of the ileum is well known. Gray, in his Textbool: of Anatomy, states that Meckel's diverticulum is present in 3 per cent. of cases. Multiple diverticula scattered along the course of the jejunum and ileum have also been described.

An indammation of any of these diverticula may be called a diverticulitis. But the diverticula, if small, do not, as a rule, give rise to srmptoms, and most frequently they are found during the course of an $x$-ray examination of the alimentary tract made for some other reason. An inflamed diverticulum of the first part of the duodenum may, however, give rise to symptoms indistinguishable from those produced by a duodenal ulcer; and an inflammation of a diverticulum of the second part of the duodenum may be the cause, by direct extension, of those cases of pancreatitis the onset of which is difficult to explain.

The diverticulitis to which $I$ wish in particular to refer is that which affects the colon, and more especially the sigmoid colon-colonic diverticulitis. Cruveilhier was the first to recognize the disease in 1849, and the condition was recognized and described also by Virchow in 1853. The first full description was that of Telling in 1908. According to James T. Case, the first case operated upon after previous radiological demonstration was published by Abbé, the radiological examination being carried out by Lewald. More recently, in this country, Spriggs and Marxer liave published a paper in the Lancet (in May, 1927), and in America a recent communication is that of James T. Case, professor of roentgenology in the Northwestern University Medical School, Chicago.

Until the past few years the disease has been considered to be rare. The more frequent adoption of $x$-ray examination as an aid in the diagnosis of discases of the colon has shown that the reverse is the truth; the discase is, in fact, more common than is perhaps generally realized.

The first step towards diverticulitis is the develepment of a condition of diverticulosis. That diverticulosis is not a congenital abnormality is, I think, prored by the rarity with which the condition is found in young people: it is essentially in adults over the age of $40 \mathrm{in}$ whom we find evidence of diverticulosis. How are the diverticula * A paper rear before the Ieeds and West Riding Medico-Chirurgical
society on Norember 22nd, 1929 . 